\title{
EL RECONOCIMIENTO EN ESPAÑA DEL SCHEME OF ARRANGEMENT DE DERECHO INGLÉS TRAS EL BREXIT
}

\author{
RECOGNITION IN SPAIN OF THE ENGLISH SCHEME \\ OF ARRANGEMENT AFTER BREXIT
}

\author{
Ángel María Ballesteros Barros* \\ Profesor Contratado Doctor acr. de Derecho Internacional Privado \\ Universidad de Cádiz \\ ORCID ID: 0000-0002-1148-3533
}

Recibido: 15.01.2021 / Aceptado: 23.01.2021

DOI: https://doi.org/10.20318/cdt.2021.5952

\begin{abstract}
Resumen: Este estudio analiza la posibilidad de reconocer y ejecutar en España un Scheme of Arrangement de Derecho inglés sancionado por un tribunal del Reino Unido en el doble escenario de que se haya iniciado antes o después del 31 de diciembre de 2020, fecha de finalización del período transitorio para el Brexit. El mecanismo de reconocimiento y ejecución en España de esta figura estará condicionado a su previa calificación desde una doble perspectiva: respecto de la naturaleza jurídicomaterial de la institución como una cuestión de derecho civil o comercial, concursal o societaria; y, desde la perspectiva procesal, respecto de la consideración de la court's order como una resolución judicial, una transacción judicial o un acto de jurisdicción voluntaria.
\end{abstract}

Palabras clave: Scheme of arrangement, reconocimiento, ejecución, Brexit.

Abstract: This article analyses the possibility of recognizing and enforcing in Spain an English Scheme of Arrangement sanctioned by a British court in the double scenario of having started before or after December 31,2020, the end date of the transitional period for Brexit. The mechanism of recognition and enforcement in Spain will be conditioned to its previous characterization from a double perspective: regarding the legal nature of the institution as a matter of civil and commercial, bankruptcy or corporate law; and on the other hand, from a procedural perspective, regarding the consideration of the court's order as a judicial resolution, a court-approved settlement or an act of voluntary jurisdiction.

Keywords: Scheme of arrangement, recognition, enforcement, Brexit.

Sumario: I. Scheme of arrangement en Derecho inglés. 1. Marco normativo. 2. Competencia judicial internacional. II. Calificación del supuesto. 1. La calificación de la naturaleza jurídicomaterial. A) Calificación concursal. B) Calificación civil o comercial. C) Calificación societaria. 2. La calificación de la naturaleza jurídico-procesal. A) Calificación como resolución judicial. B) Calificación como transacción judicial. C) Calificación como acto de jurisdicción voluntaria. III. Escenario temporal para el reconocimiento y ejecución del scheme of arrangement en España. 1. Reconocimiento del SoA incoado antes del 31 de diciembre de 2020. A) Reconocimiento en caso de tratarse de una resolución judicial. B) Reconocimiento en caso de tratarse de una transacción judicial. C) Reconocimiento en caso de tratarse de un acto de jurisdicción voluntaria. 2. Reconocimiento del SoA incoado después del 31 de diciembre de 2020. A) Reconocimiento de una resolución judicial. B) Reconocimiento de una transacción judicial. C) Reconocimiento de un acto de jurisdicción voluntaria. IV. Reconocimiento conflictual. V. Conclusiones.

*angel.ballesteros@uca.es. Agradezco a los Profesores A. RODRÍGUEZ BENOT y F. GARAU SOBRINO sus valiosos comentarios sobre el estudio. Las opiniones del trabajo son de exclusiva responsabilidad del autor. 


\section{Scheme of arrangement en Derecho inglés}

\section{Marco normativo}

1. El Scheme of Arrangement (en adelante SoA) es una figura típica del common law $w^{1}$ concebido como un procedimiento legal que permite a una sociedad llegar a un acuerdo o compromiso con sus socios (Member Scheme) o acreedores (Creditor Scheme), que, en caso de ser aprobado por la mayoría de los destinatarios y tras su aprobación judicial, resultará vinculante para ellos, hayan o no votado a favor del mismo ${ }^{2}$.

2. En el Reino Unido (en adelante RU) actualmente se regula en la Section 895 Part 26 Companies Act 2006', denominada "Arrangements and reconstructions: general", que lo define como un acuerdo entre la sociedad y sus acreedores, o cualquier clase de ellos, o entre la sociedad y sus socios, o cualquier clase de ellos ${ }^{4}$. El término arrangement puede incluir una reorganización del capital social de la compañía mediante la consolidación de acciones de diferentes clases o mediante la división de acciones en acciones de diferentes clases, o por ambos métodos ${ }^{5}$.

Junto a esta parte general, el RU ha añadido recientemente una nueva Part $26 \mathrm{~A}$ a la Section 895 Companies Act 2006 , denominada "Arrangements and reconstructions: companies in financial difficulty", que prevé disposiciones especiales que se aplican cuando la sociedad cumple simultáneamente dos condiciones: $\left(1^{\text {a }}\right)$ que se encuentre en dificultades financieras que están afectando o pueden afectar su capacidad para llevar a cabo negocios como una empresa en funcionamiento (condición A); y $\left(2^{\mathrm{a}}\right)$ que se proponga concluir un acuerdo con sus acreedores o socios con el propósito de eliminar, reducir o prevenir el efecto de cualquiera de las dificultades financieras mencionadas en la subsección 2 (condición $\mathrm{B})^{8}$.

3. En el RU existe flexibilidad en lo relativo a lo que puede ser propuesto en un SoA. En la práctica, hay tres tipos principales de SoA en función de su contenido: Transfer, Cram-down y Distribution Schemes ${ }^{9}$. A través del Transfer Scheme se transmite el negocio y los activos de una sociedad a otra de

\footnotetext{
${ }^{1}$ Aunque fueron introducidos inicialmente en Reino Unido, se han extendido a diversas jurisdicciones del common law como Australia, Hong Kong, Irlanda, Nueva Zelanda o Singapur. Sobre esta evolución, vid J. PAYne, Schemes of Arrangement: Theory, Structure and Operation, Cambridge University Press, 2014.

2 J. WINDSOR, "Una visión panorámica de los schemes of arrangement ingleses", Revista de derecho concursal y paraconcursal, 2011, núm. 15, pp. 553-563, p. 554.

${ }^{3}$ Sections 895-900 Part 26 Companies Act 2006, modificada por Regulations 2009 (S.I. 2009/1804) y Regulations 2020 (S.I. 2020/643) Fuente: https://www.legislation.gov.uk.

${ }^{4}$ Section 895 (1) Part 26 Companies Act 2006: "The provisions of this Part apply where a compromise or arrangement is proposed between a company and: (a) its creditors, or any class of them, or (b) its members, or any class of them".

${ }^{5}$ Section 895 (2) Part 26 Companies Act 2006: "Arrangement" includes a reorganisation of the company's share capital by the consolidation of shares of different classes or by the division of shares into shares of different classes, or by both of those methods".

${ }^{6}$ Sections 901A-901L Part 26A Companies Act 2006, añadidas por la Corporate Insolvency and Governance Act 2020 (c. 12), s. 49(1), Sch. 9 para. 1, y modificada por The Co-operative and Community Benefit Societies and Credit Unions (Arrangements, Reconstructions and Administration) (Amendment) and Consequential Amendments Order 2020 (S.I. 2020/744)

${ }^{7}$ Para una crítica sobre esta reforma, vid. R. Mokal, "The Difficulties with 'Financial Difficulties': The Threshold Conditions for the New Part 26A Process", Butterworths Journal of International Banking and Financial Law, 2020, vol. 35, núm. 10, pp. 662-664.

${ }^{8}$ Section 901A Part 26 Companies Act 2006:

"(1) The provisions of this Part apply where conditions A and B are met in relation to a company.

(2) Condition A is that the company has encountered, or is likely to encounter, financial difficulties that are affecting, or will or may affect, its ability to carry on business as a going concern.

(3) Condition B is that: (a) a compromise or arrangement is proposed between the company and: (i) its creditors, or any class of them, or (ii) its members, or any class of them, and (b) the purpose of the compromise or arrangement is to eliminate, reduce or prevent, or mitigate the effect of, any of the financial difficulties mentioned in subsection (2)."

${ }^{9}$ Tomamos prestada esta clasificación de J. J. González Antequera, Los Schemes of arrangement en el Derecho inglés, Civitas, 2019, pp. 56-69.
} 
nueva creación. Un Cram-down Scheme altera los términos financieros de la deuda financiera por condonación, subordinación o canje de deuda por capital (Debt-for-equity Swap). Los Distribution Schemes ofrecen un retorno de los activos a los acreedores, ofreciéndoles una alternativa más flexible a la liquidación ${ }^{10}$; suelen ser utilizados para delimitar el ámbito de las responsabilidades en caso de compañías de seguros con presencia de créditos contingentes.

4. Cabe señalar que el Derecho inglés, junto a los SoA, dispone de otros mecanismos legales para facilitar la refinanciación o reestructuración de la deuda, tales como los Company Voluntary Agreements (CVA) y la administración (Pre-packaged Administration) ${ }^{11}$, que son propiamente procedimientos concursales que se aplican al deudor insolvente, a diferencia del SoA, que puede ser utilizado también por sociedades solventes (Solvent Scheme). En la práctica, el SoA a veces se combina con el Pre-packaged Administration a través de un Transfer Scheme ${ }^{12}$.

5. De lo anterior se puede concluir que el Derecho inglés regula los SoA en una norma societaria (Companies Act 2006), que establece un procedimiento legal que permite a una sociedad alcanzar un acuerdo con sus acreedores o con sus socios con el objeto de modificar los términos de sus relaciones jurídicas y/o facilitar operaciones de refinanciación o de reestructuración societaria en diferentes contextos, tanto general (Section 895 Part 26) como de dificultad financiera (Section 895 Part 26A) ${ }^{13}$. En ambos escenarios, el SoA requiere la tramitación de un procedimiento judicial que se desarrolla en las siguientes etapas ${ }^{14}$ :

a) Solicitud (claim form) ante el tribunal competente con los términos del SoA.

b) Desarrollo del proceso: audiencias ante el tribunal y reuniones con los acreedores o socios.

c) Aprobación del SoA por los acreedores: se requiere una mayoría de acreedores que representen al menos el $75 \%$ del valor de los créditos afectados (normalmente por cada clase de acreedores)

d) Aprobación del SoA por parte del tribunal: el juez comprueba que se cumplen los requisitos legales, que se han alcanzado las mayorías necesarias, que los acreedores han actuado de buena fe durante el procedimiento ${ }^{15}$ y que el acuerdo alcanzado es razonable para una persona inteligente y honesta ${ }^{16}$.

e) Depósito del SoA sancionado judicialmente ante el Registrar of Companies ${ }^{17}$.

6. Los términos de un SoA alcanzado por la mayoría requerida y sancionado por el tribunal competente son vinculantes para todos los miembros de esas clases de créditos o acciones y, en consecuencia, obligan a la minoría disidente (Cram-down Schemes), que no obstante puede manifestar su oposición durante el proceso y, con posterioridad, plantear apelación ${ }^{18}$.

\footnotetext{
${ }^{10}$ J. WINDSOR, "Una visión panorámica de los schemes of arrangement ingleses", loc. Cit., p. 557.

${ }^{11}$ J. PAYNE, "Schemes of arrangement y reestructuración de deuda en el derecho inglés", Revista de derecho concursal y paraconcursal, 2015, núm. 22, pp. 315-328, esp. 322-327.

${ }^{12}$ Re MyTravel Group [2004] EWCA Civ 1734; Re Bluebrook Ltd [2009] EWHC 2114 (Ch).

${ }^{13}$ La nueva regulación ya se ha utilizado en Re Virgin Atlantic Airways Limited [2020] EWHC 2191 (Ch).

${ }^{14}$ Para un examen del desarrollo procesal del SoA, vid. J. J. GonzÁlez Antequera, Los Schemes of arrangement en el Derecho inglés, op. cit., pp. 89-121.

${ }^{15}$ Re Equitable Life Assurance Society [2002] EWHC 140 (Ch).

${ }^{16}$ Re National Bank Ltd [1966] 1 WLR 829.

${ }^{17}$ Section 899 (4) Part 26 Companies Act 2006: "The court's order has no effect until a copy of it has been delivered to the registrar".

${ }^{18}$ De acuerdo con lo previsto en la Section 54 Access to Justice Act 1999 y la Part 52 Civil Procedure Rules.
} 


\section{Competencia judicial internacional}

7. El Derecho inglés no tiene reglas de competencia judicial internacional en el sentido que se le otorga en los sistemas de civil la $w^{19}$, sino que el ejercicio de jurisdiction sobre el demandado está basado en un modelo de service ${ }^{20}$ y en la existencia o no de conexiones suficientes con el foro ${ }^{21}$. De acuerdo con lo previsto en la Section 895 (2) (b) Companies Act 2006'22, los tribunales ingleses podrán aprobar un SoA en relación con cualquier sociedad que pudiese ser liquidada ante ellos. Por remisión, según la Insolvency Act 1986, podrán acogerse al proceso de liquidación británico (winding up) las sociedades incorporadas e inscritas en el RU (registered companies) ${ }^{23}$, así como las sociedades no inscritas (unregistered companies $)^{24}$, lo cual ha permitido a la jurisprudencia permitir que las sociedades extranjeras planteen una reestructuración o refinanciación a través de un SoA de Derecho inglés ante tribunales del $\mathrm{RU}$, si se cumplen una serie de requisitos.

8. Entre los requisitos exigidos por la jurisprudencia británica para la sanción de un SoA presentado por una sociedad extranjera ante los tribunales del RU, la doctrina cita tres factores fundamentales ${ }^{25}$ : (1) que la sociedad extranjera acredite la existencia de una conexión suficiente con la jurisdicción británica; (2) que se produzca un resultado beneficioso para la liquidación de la sociedad, y/o (3) que el tribunal inglés pueda ejercer su jurisdicción sobre las personas interesadas en la distribución de los bienes de la sociedad.

9. El concepto de "conexión suficiente" con la jurisdicción británica ha sido interpretado en sentido amplio ${ }^{26}$. La práctica judicial ha justificado la competencia de los tribunales del RU para la sanción de un SoA acordado por sociedades extranjeras teniendo en cuenta los siguientes criterios, apreciados en conjunto o de manera aislada ${ }^{27}$ : (1) que se haya pactado una cláusula de sumisión exclusiva a los tribunales británicos; (2) que los créditos afectados por el SoA estuvieran sometidos al Derecho inglés ${ }^{28}$; (3) que el deudor tuviese un establecimiento en ese territorio; (4) que la mayoría de acreedores tuviera su domicilio en el RU; (5) que la sociedad tuviera bienes o activos sometidos a la jurisdicción inglesa; (6) que los acreedores financieros realicen operaciones o tengan sucursales en el RU; y/o (7) que el SoA será reconocido en el extranjero ${ }^{29}$.

10. El La jurisprudencia británica entiende que las sociedades extranjeras pueden plantear un SoA ante los tribunales ingleses puesto que no procede examinar dónde está el COMI de la sociedad extranjera, siendo suficiente que se demuestre una "conexión suficiente" con la jurisdicción británica ${ }^{30}$.

${ }^{19}$ A. BRIGGS, "Brexit and Private International Law: An English Perspective", Riv. dir. int. priv. proc., 2019, vol. 55, núm. 2 , pp. 261-283, esp. p. 264.

${ }^{20}$ Civil Procedure Rules 1998 (CPR), Section IV, Part 6, Rules 6.36-6.37, completadas con la Practice Direction 6B Service Out of the Jurisdiction.

${ }^{21}$ Vid. comentario de A. Dickinson, "Walking Solo - A New Path for the Conflict of Laws in England”, entrada del blog Conflictoflaws.net del 4.1.2021.

${ }^{22}$ Companies Act 2006, Section 895 (2), Part 26: “company [...] b) [...] means any company liable to be wound up under the Insolvency Act 1986 (c. 45) or the Insolvency (Northern Ireland) Order 1989 (S.I. 1989/2405 (N.I. 19))."

${ }^{23}$ Insolvency Act 1986, Section 73 (1) Part IV: "this Part applies to the winding up of a company registered under the Companies Act 2006 in England and Wales or Scotland."

${ }^{24}$ Insolvency Act 1986, Section 220 Part V: "for the purposes of this Part unregistered company includes any association and any company, with the exception of a company registered under the Companies Act 2006 in any part of the United Kingdom."

${ }_{25}$ J. J. GonzÁlez Antequera, Los Schemes of arrangement en el Derecho inglés, op. cit., pp. 160-167.

${ }^{26}$ F. J. Garcimartín AlfÉrez, "La eficacia en España de los schemes of arrangement ingleses", Revista de derecho concursal y paraconcursal, 2010, núm. 13, pp. 383-398, p. 386.

${ }^{27}$ Re Drax Holdings Ltd (2003) EWHC 2743 (Ch)

${ }^{28}$ Re Real Estate Developement Co (1991) BCLC 210.

${ }^{29}$ Re Gallery Capital SA [2010] WL 4777509 (Ch).

${ }^{30}$ Re Rodenstock GmbH (2011) EWHC 1104 (Ch); Re Primacom Holdings GmbH (2011) EWHC 3746 (Ch) 
Algunos autores justifican este Forum Shopping por las ventajas del SoA en el supuesto de ausencia de soluciones similares en su Derecho interno ${ }^{31}$.

Con base en estos criterios de conexión suficiente, varias sociedades españolas han visto aprobados sus SoA por parte de tribunales del $\mathrm{RU}^{32}$, con algunas voces críticas en la doctrina española ${ }^{33}$. En nuestra opinión, las normas de jurisdicción británicas referidas deben ser analizadas con la perspectiva de la posible aplicación de los instrumentos comunitarios ${ }^{34}$, al menos para los procedimientos de SoA iniciados antes del final del periodo transitorio del Brexit. Analizaremos esta cuestión en el apartado III, dado que con carácter previo debemos calificar el supuesto objeto de estudio, lo cual va a condicionar el instrumento aplicable.

\section{Calificación del supuesto}

11. A partir del Brexit, el reconocimiento del Scheme of arrangement estará condicionado a la previa calificación del supuesto de hecho objeto de estudio aplicando las técnicas metodológicas propias del Derecho internacional privado de los Estados miembros ${ }^{35}$. Desde la óptica del sistema español, hemos de calificar la court's order sancionando un SoA desde una doble perspectiva: por un lado, respecto de la naturaleza jurídico-material de la institución (apartado 1); y por otro lado la perspectiva procesal, respecto de la consideración de la court's order como una resolución judicial, una transacción judicial o un acto de jurisdicción voluntaria (apartado 2).

\section{La calificación de la naturaleza jurídico-material}

12. El Derecho inglés contempla la utilización del SoA por parte de las sociedades para alcanzar un acuerdo con sus acreedores o con sus socios en diferentes contextos, tanto concursales como no concursales, facilitando operaciones de refinanciación o de reestructuración societaria. Dependiendo de la naturaleza jurídico-material del SoA utilizado, para el reconocimiento y ejecución en España del SoA de Derecho inglés se utilizará un instrumento u otro. Existe una triple posibilidad de calificación del SoA: por una parte, considerarlo como una institución de naturaleza concursal relacionada con el Derecho de insolvencia (apartado A); por otra parte, considerarlo como una institución de naturaleza civil o comercial no vinculada necesariamente con el Derecho de insolvencia (apartado B); por último, considerarlo como una cuestión societaria (apartado C)

\section{A) Calificación concursal}

13. En primer lugar, conviene considerar la posibilidad de defender que el SoA es una institución relacionada con el Derecho de insolvencia por ser utilizada de manera habitual en periodos preconcursales de reestructuración y refinanciación de sociedades. De acuerdo con esta calificación, los

\footnotetext{
${ }^{31}$ Por todos, vid J. PAYNe, "Cross-border Schemes of Arrangement and Forum Shopping”, European Business Organization Law Review, 2013, vol. 4, núm. 14, pp. 563-589.

${ }^{32}$ Re La Seda de Barcelona SA (2010) EWHC 1364 (Ch); Re Metrovacesa SA (2011) EWHC 1014 (Ch); Re Codere Finance Ltd (2015) EWHC 3778 (Ch). Vid. comentarios en J. J. GonZÁlez Antequera, Los Schemes of arrangement en el Derecho inglés, op. cit., pp. 327-342.

${ }^{33}$ Por todos, vid. E. Torralba Mendiola y Á. Carrasco, "Schemes of arrangement ingleses para sociedades españolas: una crítica", Revista de derecho concursal y paraconcursal, 2011, núm. 14, pp. 349-362.

${ }^{34}$ De esta opinión, L. C. Ho, "A Restatement of the English Court's Jurisdiction to Sanction a Scheme of Arrangement", Corporate Rescue and Insolvency, 2009, vol. 1, núm. 3, pp. 1-6.

${ }^{35}$ L. Carballo Piñeiro, "La insolvencia transfronteriza en la Unión Europea y el Reino Unido tras el Brexit", Revista de derecho concursal y paraconcursal, núm. 27, 2017, pp. 493-511, p. 509.
} 
mecanismos potencialmente aplicables para el reconocimiento y ejecución del SoA sancionado por un tribunal inglés en España serían, dependiendo del momento en que se haya iniciado el procedimiento, el Reglamento (UE) 2015/848 del Parlamento Europeo y del Consejo, de 20 de mayo de 2015, sobre procedimientos de insolvencia [en lo sucesivo RI] ${ }^{36}$, o el Texto Refundido de la Ley concursal [en adelante TRLC], aprobado por el Real Decreto Legislativo $1 / 2020^{37}$.

14. En lo que respecta al RI, su artículo 1 (1) señala que se aplica a los procedimientos colectivos públicos regulados en la legislación en materia de insolvencia y en los que, a efectos de rescate, reestructuración de la deuda, reorganización o liquidación: (a) se desapodere a un deudor total o parcialmente de sus bienes y se nombre a un administrador concursal; (b) los bienes y negocios de un deudor se sometan a control o supervisión judicial, o (c) un órgano jurisdiccional acuerde una suspensión temporal de los procedimientos de ejecución individual para facilitar las negociaciones entre el deudor y sus acreedores. A este respecto, el Considerando 16 RI señala que "los procedimientos que se basen en disposiciones generales del Derecho de sociedades que no estén concebidas exclusivamente para situaciones de insolvencia no deben considerarse procedimientos basados en la legislación en materia de insolvencia".

15. Por otro lado, el artículo 1 (1) in fine RI establece que "los procedimientos a que se refiere el presente apartado se enumeran en el anexo A." A este respecto, el Considerando 9 RI señala que esta lista es exhaustiva y que "los procedimientos nacionales de insolvencia que no estén enumerados en el anexo A deben quedar excluidos del presente Reglamento."

Esta postura coincide con la mayoritaria en la doctrina anglosajona $\mathrm{a}^{38} \mathrm{y}$ con la jurisprudencia de los tribunales del Reino Unido ${ }^{39}$.

16. Por los argumentos expresados, entendemos que el SoA no cumple con los requisitos materiales exigidos por el artículo 1 (1) RI para su aplicabilidad, puesto que el SoA no fue incluido entre los procedimientos de insolvencia mencionados en su Anexo A del RI, no supone un procedimiento colectivo público que afecte a la totalidad del pasivo, no implica un proceso de desapoderamiento del deudor ni tampoco el nombramiento de un administrador concursal, ni puede considerarse como una institución exclusiva del Derecho concursal, sino que está encuadrado en la Section 895 (Parts 26 y 26A) de la Companies Act (2006) y no en la Insolvency Act, siendo utilizado para acuerdos de refinanciación no necesariamente vinculados a un procedimiento de insolvencia.

17. Sin embargo, la inclusión de un nuevo tipo de SoA de la Part 26A Companies Act (2006) basado en dificultades financieras podría matizar esta tradicional calificación, pues podríamos considerar que este apartado regula una situación pre-concursal compatible con un posterior procedimiento de insolvencia. Esta calificación pre-concursal tendría un mayor fundamento en el supuesto de que la sociedad atravesase dificultades financieras y solicitase el SoA basándose en la Part $26 \mathrm{~A}$ de la Section 895 Companies Act 2006, con la pretensión de concluir acuerdos con sus acreedores en el marco de un proceso de reestructuración o refinanciación.

18. En todo caso, aunque compartiéramos parcialmente esta posible calificación concursal, de acuerdo con los términos de las disposiciones transitorias del Acuerdo sobre el Brexit, el RI solo podría ser aplicable "a los procedimientos de insolvencia y a las acciones a que se refiere el artículo 6, apartado 1, de dicho Reglamento, siempre que el procedimiento principal se haya incoado antes del final del periodo transitorio." Es decir, para que fuera aplicable el RI sería necesario que el SoA tuviera su

\footnotetext{
${ }^{36}$ DOUE L 141, de 5.6.2015.

${ }^{37}$ BOE núm. 127 de 7.5.2020, artículos 742 a 748.

${ }^{38}$ Por todos, vid I. Mevorach y A. Walters, "The Characterization of Pre-insolvency Proceedings in Private International Law”, European Business Organization Law Review, 2020, vol. 4, núm. 21, pp. 855-894, esp. 875-880. No obstante, estos autores ponen de manifiesto los problemas de calificación derivados de la naturaleza híbrida de los SoA como institutos preconcursales cuando en la práctica se combinan con otros procesos propios del Derecho concursal.

${ }^{39}$ Re DAP Holding NV (2005) EWHC 2092 (Ch); Re Drax Holdings Ltd (2003) EWHC 2743 (Ch)
} 
fundamento en la Part $26 A$ de la Section 895 Companies Act 2006 y, simultáneamente, que la sociedad hubiera solicitado la apertura de un procedimiento de insolvencia principal antes del final del periodo transitorio, lo cual reduce mucho en la práctica la posible aplicación del RI.

A partir del 1 de enero de 2021, el RI ha dejado de aplicarse entre el RU y la UE y, por tanto, la calificación que el tribunal español haya de realizar respecto de la institución del SoA se practicará según el criterio del Derecho español como lex fori (ex artículo 12.1 Código civil). En consecuencia, el tribunal español podría interpretar que el instrumento aplicable sería el TRLC, al calificar como concursal el SoA como un procedimiento de homologación de acuerdos de refinanciación. Esta cuestión será abordada en el apartado III.2, al cual nos remitimos.

\section{B) Calificación civil o comercial}

19. En caso de que interpretemos que el SoA no tiene calificación concursal en los supuestos que no estén vinculados a un procedimiento de insolvencia, se cuestiona si en consecuencia tendría naturaleza civil o comercial. Para ello, el texto de referencia para el reconocimiento en España de una resolución judicial de un tribunal del RU en materia civil o mercantil sería, al menos hasta el 31 de diciembre de 2020, el Reglamento (UE) n ${ }^{\circ}$ 1215/2012 del Parlamento Europeo y del Consejo de 12 de diciembre de 2012 relativo a la competencia judicial, el reconocimiento y la ejecución de resoluciones judiciales en materia civil y mercantil [RB I Bis $]^{40}$.

20. En lo que se refiere al RB I Bis, si se considerase que el SoA no tiene naturaleza jurídicomaterial concursal ni deriva necesariamente de un procedimiento de insolvencia, cabría plantearse si la resolución adoptada por el tribunal inglés sancionando el SoA es susceptible de ser reconocida y ejecutada conforme a las reglas del RB I Bis, por cuanto no se encuentra excluida expresamente por el artículo 1 (2) (b) RB I Bis, al no tratarse de un procedimiento referido a "la quiebra, los convenios entre quebrado $y$ acreedores, $y$ demás procedimientos análogos". De acuerdo con la jurisprudencia del TJUE, los instrumentos comunitarios del RB I Bis y el RI "deben interpretarse de tal manera que se evite todo solapamiento entre las normas jurídicas que ambos textos establecen, así como todo vacio jurídico" ${ }^{41}$. En consecuencia, la exclusión del SoA del ámbito material del RI parece implicar la inclusión en el ámbito del RB I Bis.

A salvo de la eventual consideración preconcursal del SoA basado en la Part 26A, el SoA como acuerdo de refinanciación con los acreedores solicitado de conformidad con la Part 26 se refiere a una cuestión propia de Derecho civil contractual incluida en el concepto de Derecho privado, por lo que entraría dentro del ámbito de aplicación material definido en el artículo 1 (1) RB I Bis, siempre que se respetase el ámbito temporal de aplicación del RB I Bis.

A partir del 1 de enero de 2021, el RB I Bis dejará de aplicarse a los SoA de Derecho inglés. En consecuencia, debemos analizar si existe algún otro instrumento internacional aplicable.

21. En lo que respecta al Convenio de Lugano 2007, esta posibilidad aún no es susceptible de aplicarse pues la solicitud de adhesión depositada por el RU el 8 de abril de 2020 aún debe ser aceptada por los Estados Partes. Caso de prosperar, esta opción permitiría en el futuro mantener la pirámide de foros del RB I Bis entre el RU y los Estados miembros de la UE, Islandia, Noruega y Suiza ${ }^{42}$.

22. En relación con el Convenio de la Haya de 2005 sobre acuerdos de elección de foro (en adelante CH 2005), el RU ha depositado su adhesión el 28 septiembre 2020. En consecuencia, a partir

\footnotetext{
${ }^{40}$ DOUE L 351, de 20.12.2012.

${ }^{41}$ STJUE de 19.04.2012, F-Tex, C-213/10 [ECLI:EU:C:2012:215], apartado 29; STJUE de 09.11.2017, Tünkers France y Tünkers Maschinenbau, C-641/16 [ECLI:EU:C:2017:847], apartado 17.

${ }^{42}$ Algunos autores incluso defienden que, en caso de un Brexit sin acuerdo, existen argumentos para defender la aplicación del Convenio Lugano 1988. Vid. R. Rodriguez y P. Gubler, "Recognition of a UK Solvent Scheme of Arrangement in Switzerland and under the Lugano Conventions”, IPRAx, 2020, vol. 4, pp. 372-378.
} 
del 1 enero 2021 este Convenio se aplica a los acuerdos de sumisión expresa a los tribunales del RU firmados desde esa fecha. En cambio, los acuerdos firmados hasta el 31 de diciembre de 2020 seguirán los trámites previstos en el RB I Bis, de acuerdo con las normas transitorias del Acuerdo sobre el Brexit. De acuerdo con su artículo 1 (1), el CH 2005 se aplicará a los acuerdos exclusivos de elección de foro que se celebren en materia civil y comercial. Su artículo 2 (2) prevé que no se aplicará a los acuerdos exclusivos de elección de foro relativos a "la insolvencia, los convenios entre insolvente y acreedores y materias análogas". No puede considerarse que los SoA puedan entrar dentro de esta exclusión, por los argumentos expresados en el apartado anterior, por lo que parte de la doctrina aboga por la plena aplicación del CH 2005 a los acuerdos de sumisión expresa incorporados a un SoA ${ }^{43}$.

23. En defecto de instrumento internacional aplicable, para el reconocimiento y ejecución del SoA en España se aplicaría la norma propia del régimen autónomo español, en la materia la Ley 29/2015, de 30 de julio, de cooperación jurídica internacional en materia civil [LCJI $]^{44}$, cuyo régimen abordaremos en el apartado III.

\section{C) Calificación societaria}

24. Finalmente, cabría examinar la hipotética posibilidad de que un SoA acordado entre los socios de una compañía pudiera otorgarle una calificación diferente de la civil o comercial. Pues bien, el hecho de que un SoA se acordase en el ámbito de una reestructuración societaria no le privaría de tratarse de una cuestión de Derecho privado con las mismas consideraciones realizadas hasta ahora para la calificación civil o comercial. La única diferencia, que podría tener trascendencia en cuanto al régimen de reconocimiento, sería en relación con la competencia judicial internacional, puesto que ciertos acuerdos en materia societaria pudieran ser susceptibles de ser incluidos en el foro exclusivo del artículo 24 (2) RB I Bis respecto de la validez, nulidad o disolución de sociedades y personas jurídicas, o la validez de las decisiones de sus órganos, en caso de ser aplicable este instrumento. Por ejemplo, esta cuestión podría suscitarse en el marco de una liquidación societaria no concursal ${ }^{45}$. En todo caso, la calificación societaria de un SoA no alteraría las reglas sobre el régimen de eventual reconocimiento y ejecución, pues éstas no distinguen si se trata de materia civil, comercial o societaria.

25. Cuestión diferente a las anteriores es si el SoA objeto de estudio cumple los requisitos jurídico-procesales para ser considerado una resolución judicial cuyo reconocimiento esté sometido al RB I Bis, a otro instrumento internacional o, en su defecto, a las reglas de la LCJI. Esta calificación debe ser examinada en el siguiente apartado.

\section{La calificación de la naturaleza jurídico-procesal}

26. Dependiendo de la naturaleza jurídico-procesal de la institución, para el reconocimiento y ejecución en España del SoA de Derecho inglés se utilizará un instrumento u otro. Existe una triple posibilidad de calificación: considerarlo como una resolución judicial dictada en un procedimiento de jurisdicción contenciosa (apartado A); como una transacción judicial (apartado B); o como un acto de jurisdicción voluntaria (apartado C).

\footnotetext{
${ }^{43}$ J. Marshall, J. Ferguson y L. Aconley, “Brexit: what next for cross-border restructurings and insolvencies?”, Corporate Rescue and Insolvency, 2016, núm. 4, pp. 149-151. Con dudas sobre esta interpretación, vid. L. CARBAllo PiñEIRo, "La insolvencia transfronteriza en la Unión Europea y el Reino Unido tras el Brexit”, loc. Cit., p. 510.

${ }^{44}$ BOE núm. 182, de 31.07.2015.

${ }^{45}$ L. C. Ho, "A rational basis of jurisdiction over EEA insurers' solvent schemes that the WFUM decision could be, but isn't”, Insolvency Law \& Practice, 2006, vol. 22, pp. 145-149.
} 


\section{A) Calificación como resolución judicial}

27. De acuerdo con los términos del artículo 2 (a) RB I bis, por resolución se entiende "cualquier decisión adoptada por un órgano jurisdiccional de un Estado miembro, con independencia de la denominación que reciba, tal como auto, sentencia, providencia o mandamiento de ejecución, así como el acto por el cual el secretario judicial liquide las costas del proceso." Se trata de un concepto amplio de resolución pues se fundamenta en el principio de confianza recíproca de la justicia en la UE, debiendo el tribunal del Estado miembro requerido aceptar la resolución judicial dictada por el Estado miembro de origen sin examinar o revisar el fondo de la misma ${ }^{46}$.

28. De acuerdo con este concepto amplio, a priori no podríamos excluir el SoA objeto de análisis de la definición de resolución judicial del RB I Bis. No obstante, algunos autores consideran que el SoA no cumple con el requisito de tratarse de una resolución recaída en un procedimiento contradictorio dentro del cual el Tribunal "en el ejercicio de su potestad jurisdiccional, resuelva sobre los puntos controvertidos entre las partes" $"$. De acuerdo con el razonamiento expuesto por F. J. GARCIMARTín AlfÉREZ, "el scheme no es un tipo de procedimiento que responda exactamente a ese esquema. Su naturaleza no es propiamente contenciosa, el deudor no interviene como actor presentado una demanda, ni los acreedores afectados son citados como demandados." ${ }^{48}$

29. Frente a ello, cabe alegar que el propio TJUE tiene establecido que "aunque la resolución judicial haya sido dictada tras una primera fase del procedimiento no contradictoria, pudo ser objeto de un debate contradictorio antes de que se suscitara la cuestión de su reconocimiento y ejecución con arreglo al Convenio" (léase RB I Bis) ${ }^{49}$. En particular, el TJUE exige que "las resoluciones cuya ejecución se solicita en otro Estado miembro hayan sido dictadas en un procedimiento judicial que ofrezca garantías de independencia e imparcialidad y respete el principio de contradicción" ${ }^{50}$.

A este respecto, conviene señalar que la resolución dictada por el tribunal inglés sancionando el SoA habrá sido dictada tras una fase procesal contradictoria, con posibilidad de debate contradictorio en el curso de la audiencia de los acreedores afectados por el SoA, y con posibilidad de apelación ante los tribunales superiores ingleses frente a la resolución emitida antes de que se someta a reconocimiento la misma. Por lo cual no vemos motivos para negar el carácter de resolución judicial que le atribuye el RB I Bis.

30. En caso de que no resultara de aplicación del RB I Bis, habría que considerar la aplicación del CH 2005 en el caso de que se hubiera incluido una cláusula de sumisión expresa a los tribunales del RU en un acuerdo posterior al 1 de enero de 2021. A estos efectos, el artículo 4 (1) CH 2005 considera resolución judicial "toda decisión en cuanto al fondo emitida por un tribunal, cualquiera que sea su denominación, incluyendo sentencias o autos, así como la determinación de costas o gastos por el tribunal (incluyendo el secretario del tribunal), siempre que la determinación se refiera a una decisión sobre el fondo que sea susceptible de ser reconocida o ejecutada en virtud de este Convenio". Dada su redacción casi idéntica al artículo 2 (a) RB I bis, damos por reproducidos los argumentos expresados con respecto a la consideración del SoA como una resolución judicial a los efectos de la eventual aplicación del CH 2005.

31. Por último, en relación con el régimen autónomo, el artículo 43 (a) LCJI define resolución como "cualquier decisión adoptada por un órgano jurisdiccional de un Estado, con independencia de su denominación, incluida la resolución por la cual el secretario judicial o autoridad similar liquide

\footnotetext{
${ }^{46}$ STJUE de 15 noviembre 2012, asunto C-456/11, Gothaer [ECLI:EU:C:2012:719], apartado 36.

${ }^{47}$ STJCE de 21 de mayo de 1980, asunto C-125/79, Denilauler [ECLI:EU:C:1980:130], apartado 9.

${ }^{48}$ F. J. Garcimartín Alférez, "La eficacia en España de los schemes of arrangement ingleses", loc. cit., p. 389.

${ }^{49}$ STJUE de 14 de octubre de 2004, asunto C-39/02, Moersk [ECLI:EU:C:2004:615], apartado 50; STJCE de 13 de julio de 1995, asunto C-474/93, Hengst [ECLI:EU:C:1995:243], apartado 14.

${ }^{50}$ STJUE de 9 de marzo de 2017, asunto C-551/15, Pula Parking [ECLI:EU:C:2017:193], apartado 54.
} 
las costas del proceso". Por los argumentos expuestos, tampoco el régimen interno español excluye la court's order inglesa del concepto de resolución judicial.

\section{B) Calificación como transacción judicial}

32. En el hipotético caso de que se considerase que la court's order inglesa no reuniese los requisitos para ser considerada una resolución judicial, no por ello dejaría de aplicarse el régimen previsto en el capítulo III del RB I Bis para reconocer y ejecutar en España la decisión del Tribunal inglés, por cuanto, de manera subsidiaria, se podrían reconducir a la figura de la transacción judicial definida en el artículo 2 (b) RB I Bis como "un pacto aprobado por un órgano jurisdiccional de un Estado miembro o concluido ante un órgano jurisdiccional de un Estado miembro en el curso del procedimiento".

33. En este caso, su reconocimiento podría realizarse a través del mecanismo previsto en materia de exequátur para las transacciones judiciales y documentos públicos con fuerza ejecutiva del capítulo IV del RB I Bis, puesto que el artículo 59 RB I Bis establece que "las transacciones judiciales que tengan fuerza ejecutiva en el Estado miembro de origen serán ejecutadas en los demás Estados miembros en las mismas condiciones que los documentos públicos".

Entre los autores que analizan este posible encuadramiento, F. J. GArCimartín Alférez afirma que "un scheme no es más que una transacción judicial en la que la voluntad individual del acreedor ha sido reemplazada por una voluntad colegiada. El consentimiento individual de cada acreedor se sustituye ex lege por el consentimiento de una mayoría cualificada que se entiende representa adecuadamente el interés colectivo". No obstante, este autor entiende que el consentimiento individual así sustituido no encaja en el concepto de transacción judicial del artículo $58^{51}$.

34. En caso de aplicarse el CH 2005, el artículo 12 señala que "las transacciones judiciales que ha aprobado un tribunal de un Estado contratante, designado en un acuerdo exclusivo de elección de foro o que han sido celebradas ante ese tribunal en el curso del procedimiento y que son ejecutorias al igual que una resolución en el Estado de origen, serán ejecutadas en virtud del presente Convenio de igual manera que una resolución."

Aunque el CH 2005 no define el concepto de transacción judicial, el Informe explicativo HaRTLEY / Dogauchi expone que "las transacciones judiciales son desconocidas en los países del common law [...] Una transacción judicial difiere de una consent order según el common law (una orden dictada por el tribunal con el consentimiento de ambas partes), porque una consent order es una resolución y puede ser reconocida y ejecutada como tal en virtud del artículo 8 del Convenio." 52

\section{C) Calificación como acto de jurisdicción voluntaria}

35. En el hipotético caso de que se considerase que el SoA no reuniese los requisitos para ser considerada ni una resolución ni una transacción judicial, la última alternativa posible a estudiar sería si pudiese ser considerado como un acto de jurisdicción voluntaria acordado por autoridad extranjera ${ }^{53}$.

36. En Derecho español, el artículo 1 de la Ley 15/2015, de 2 de julio, de Jurisdicción Voluntaria[LJV $]^{54}$ considera actos de jurisdicción voluntaria "todos aquellos que requieran la intervención de un órgano jurisdiccional para la tutela de derechos e intereses en materia de Derecho civil y mercantil, sin que exista controversia que deba sustanciarse en un proceso contencioso."

\footnotetext{
${ }^{51}$ F. J. Garcimartín AlfÉrez, "La eficacia en España de los schemes of arrangement ingleses”, loc. cit., p. 390.

52 Informe explicativo del CH 2005, elaborado por los Profesores T. HARTLEY y M. DogaUCHI, párrafo 207.

${ }^{53}$ Por todos, vid. J. J. GonzÁlez Antequera, Los Schemes of arrangement en el Derecho inglés, op. cit., pp. $318-327$.

${ }^{54}$ BOE núm. 158, de 03.07.2015.
} 
37. En caso de ser considerado como un acto de jurisdicción voluntaria, el reconocimiento y ejecución en España de la decisión del Tribunal inglés aprobando el SoA seguiría los trámites previstos en la LCJI, por remisión del artículo 12 (1) LJV, que establece que "los actos de jurisdicción voluntaria acordados por las autoridades extranjeras que sean firmes surtirán efectos en España y accederán a los registros públicos españoles previa superación de su reconocimiento conforme a lo dispuesto en la legislación vigente".

\section{Escenario temporal para el reconocimiento y ejecución del scheme of arrangement en España}

38. Desde una perspectiva temporal, en nuestro estudio utilizaremos el método diacrónico, esto es, expondremos la síntesis de los resultados obtenidos en nuestro análisis científico retrospectivo para establecer las consecuencias que el Brexit tiene en la aplicación del instrumento de reconocimiento una vez producida la salida del RU de la UE. Se plantean grandes incertidumbres respecto a los efectos extraterritoriales de los procedimientos británicos preconcursales y extraconcursales utilizados en la reorganización y refinanciación de empresas de actividad internacional, incluidos los SoA ${ }^{55}$.

39. En nuestro análisis deberemos distinguir un doble escenario temporal, en función de que el procedimiento del SoA se haya iniciado antes o después del 31 de diciembre de 2020, tras la finalización del periodo transitorio del Brexit.

\section{Reconocimiento del SoA incoado antes del 31 de diciembre de 2020}

40. En cuanto a los procesos de SoA pendientes de aprobación iniciados antes del Brexit o durante el período transitorio, deberemos tener en cuenta los términos del Acuerdo sobre la retirada del Reino Unido de Gran Bretaña e Irlanda del Norte de la Unión Europea y de la Comunidad Europea de la Energía Atómica, de 24 de enero de $2020^{56}$, en el cual se contienen las siguientes disposiciones transitorias para el Brexit:

“1. En el Reino Unido, y en los Estados miembros en las situaciones que incumban al Reino Unido, respecto de los procesos judiciales incoados antes del final del periodo transitorio y respecto de los procesos o acciones que tengan relación con tales procesos judiciales con arreglo a los artículos 29, 30 y 31 [normas sobre litispendencia y conexidad] del Reglamento (UE) $n^{\circ}$ 1215/2012 [...] se aplicarán los actos o disposiciones siguientes:

a) las disposiciones en materia de competencia judicial del Reglamento (UE) $n^{\circ}$ 1215/2012;

[...]

2. En el Reino Unido, y en los Estados miembros en las situaciones que incumban al Reino Unido, se aplicarán los actos o disposiciones siguientes respecto del reconocimiento y la ejecución de resoluciones, documentos públicos, acuerdos y transacciones judiciales, como se dispone a continuación:

a) el Reglamento (UE) n.o 1215/2012 se aplicará al reconocimiento y la ejecución de las resoluciones dictadas en procesos judiciales incoados antes del final del período transitorio, así como a los documentos públicos formalizados o registrados oficialmente y las transacciones judiciales aprobadas o celebradas antes del final del periodo transitorio.

3. En el Reino Unido, así como en los Estados miembros en situaciones que incumban al Reino Unido, las siguientes disposiciones se aplicarán como sigue:

$[\ldots]$

c) el Reglamento (UE) 2015/848 del Parlamento Europeo y del Consejo se aplicará a los procedimientos de insolvencia y a las acciones a que se refiere el artículo 6, apartado 1, de dicho Reglamento, siempre que el procedimiento principal se haya incoado antes del final del periodo transitorio."

\footnotetext{
${ }^{55}$ Á. Espiniella Menéndez, "Brexit e insolvencia transfronteriza", Anuario Español de Derecho Internacional Privado, 2017, t. XVII, pp. 91-123, p. 96.

${ }^{56}$ DOUE L 29, de 31.1.2020.
} 
41. En consecuencia, al SoA incoado antes del 31 de diciembre de 2020 se le aplicarán las normas del RB I Bis, en función de la calificación jurídico-procesal que otorguemos a la institución: (a) si consideramos que se trata de una resolución judicial, se le aplicarían las normas sobre reconocimiento y declaración de ejecutividad de resoluciones en caso de que hayan sido dictadas en procesos iniciados antes de finalizado el período transitorio; (b) si consideramos que se trata de una transacción judicial, se le aplicarían las normas relativas a documentos públicos y acuerdos y transacciones judiciales, siempre que hayan sido dictadas, formalizadas o registradas, aprobadas o celebradas antes de que haya finalizado el período transitorio.

\section{A) Reconocimiento en caso de tratarse de una resolución judicial}

42. Se le aplicarían las normas sobre reconocimiento y declaración de ejecutividad de resoluciones judiciales previstas en el capítulo III RB I Bis (artículos 36 a 57), en caso de que hayan sido dictadas en procesos iniciados antes de finalizado el período transitorio.

43. Como regla general, las resoluciones dictadas por un tribunal de un Estado miembro de origen (a estos efectos, RU) se reconocen automáticamente en el Estado miembro requerido (en este caso, España) sin necesidad de que se desarrolle ningún procedimiento ad hoc de homologación, extendiendo sus efectos a este último en virtud de la tesis de extensión de efectos ${ }^{57}$.

44. En cuanto a la ejecución, si la resolución es ejecutiva en el Estado miembro de origen extiende sus efectos al Estado miembro requerido, debiendo ser ejecutada en este en las mismas condiciones que si se hubieran dictado en el Estado miembro requerido [artículo 41 (1) RB I Bis].

\section{B) Reconocimiento en caso de tratarse de una transacción judicial}

45. Se le aplicarían las normas relativas a documentos públicos y acuerdos y transacciones judiciales previstas en el capítulo IV RB I Bis (artículos 58 a 60), siempre que hayan sido dictadas, formalizadas o registradas, aprobadas o celebradas antes de que haya finalizado el período transitorio. La ejecución de un documento público solo podrá denegarse en caso de que sea manifiestamente contraria al orden público en el Estado miembro requerido [artículo 58 (1) RB I Bis]

46. El problema que plantea la consideración como transacción judicial es que en caso de que, para que se aplique el RB I Bis de acuerdo con las normas transitorias previstas en el Acuerdo para el Brexit, se requiere que hayan sido dictadas, formalizadas o registradas, aprobadas o celebradas antes de que haya finalizado el período transitorio, supuesto que resulta difícil considerar como cumplido en el caso objeto de estudio. En caso de entender que en el presente supuesto este requisito procesal no se cumpliese, el reconocimiento y ejecución se seguiría por los trámites previstos en la LCJI.

\section{C) Reconocimiento en caso de tratarse de un acto de jurisdicción voluntaria}

47. En este supuesto, sería más discutible la aplicación del RB I Bis para reconocer y ejecutar en España la decisión del Tribunal inglés, debiendo seguir los trámites previstos en la LCJI, por remisión del artículo 12 (1) LJV, que establece que "los actos de jurisdicción voluntaria acordados por las autoridades extranjeras que sean firmes surtirán efectos en España y accederán a los registros públicos españoles previa superación de su reconocimiento conforme a lo dispuesto en la legislación vigente".

${ }^{57}$ STJUE de 4 de febrero de 1988, asunto C-145/86, Hoffmann [ECLI:EU:C:1988:61], apartado 9. 
48. Conviene tener en cuenta que, de acuerdo con lo previsto en el artículo 12 (2) LJV, el reconocimiento en España de los actos de jurisdicción voluntaria acordados por las autoridades extranjeras sólo se denegará en estos casos:

a) Si el acto hubiera sido acordado por autoridad extranjera manifiestamente incompetente. Se considerará que la autoridad extranjera es competente si el supuesto presenta vínculos fundados con el Estado extranjero cuyas autoridades han otorgado dicho acto. Se considerará, en todo caso, que las autoridades extranjeras son manifiestamente incompetentes cuando el supuesto afecte a una materia cuya competencia exclusiva corresponda a los órganos judiciales o autoridades españolas.

b) Si el acto hubiera sido acordado con manifiesta infracción de los derechos de defensa de cualquiera de los implicados.

c) Si el reconocimiento del acto produjera efectos manifiestamente contrarios al orden público español.

d) Si el reconocimiento del acto implicara la violación de un derecho fundamental o libertad pública de nuestro ordenamiento jurídico.

\section{Reconocimiento del SoA incoado después del 31 de diciembre de $\mathbf{2 0 2 0}$}

49. Hemos de señalar igualmente que ni en el Acuerdo de comercio y cooperación concluido entre la UE y el RU ${ }^{58}$ ni tampoco en la legislación interna española ${ }^{59}$ existen disposiciones sobre cooperación judicial en materia civil y mercantil a aplicar en el periodo post-Brexit. Así las cosas, en caso de que el SoA se haya iniciado a partir del 1 de enero de 2021, el reconocimiento del SoA se llevaría a efecto a través de los instrumentos jurídicos previstos en el régimen autónomo del sistema español de Derecho internacional privado, puesto que han dejado de aplicarse los instrumentos comunitarios (entre otros, el RB I Bis y el RI) para el reconocimiento y ejecución de las resoluciones adoptadas por los tribunales ingleses, cualquiera que sea la forma jurídico-procesal que adopten (resolución judicial, transacción judicial o acto de jurisdicción voluntaria). De lo anterior se derivan importantes consecuencias:

a) Las resoluciones del RU ya no gozarán de la libertad de circulación de resoluciones judiciales ni del principio de confianza recíproca que se predica de las decisiones adoptadas en el espacio judicial comunitario entre los Estados miembros, tanto en lo que se refiere al ámbito de la competencia judicial internacional como del mecanismo de reconocimiento y ejecución de resoluciones.

b) La calificación que el tribunal español haya de realizar respecto de la institución del SoA se practicará según el criterio del Derecho español como la lex fori (ex artículo 12.1 Código civil español), lo cual podría derivar en un conflicto de calificaciones respecto de la naturaleza jurídico-material y jurídico-procesal del SoA en España. Por ejemplo, el tribunal español podría calificar como concursal los procedimientos de homologación de acuerdos de refinanciación, aplicando el TRLC en lugar de la LCJI o la LJV.

c) El mecanismo de reconocimiento del SoA variará en función de la calificación material y procesal que otorguemos a la institución del SoA.

\footnotetext{
${ }^{58}$ DOUE L 444, de 31.12.2020.

${ }^{59}$ Real Decreto-ley 38/2020, de 29 de diciembre, por el que se adoptan medidas de adaptación a la situación de Estado tercero del Reino Unido de Gran Bretaña e Irlanda del Norte tras la finalización del periodo transitorio (BOE núm. 340, de 30.12.2020). Vid. comentarios de F. Garau Sobrino, entrada del blog Conflictuslegum de 30.12.2020, y A. Iriarte IBARgüEn, "España y Reino Unido tras el Brexit. Medidas temporales", Diario La Ley, núm. 9763, 4.1.2021.
} 


\section{A) Reconocimiento de una resolución judicial}

a) En materia civil o comercial:

50. Se le aplicarían las normas sobre reconocimiento y declaración de ejecutividad de las resoluciones judiciales previstas en la LCJI (artículos 44 a 55).

51. Cabe destacar que el artículo 44 (4) LCJI acoge la teoría de la equivalencia de efectos, al prever que si la resolución extranjera contuviera una medida que es desconocida en el ordenamiento jurídico español se adoptará una medida propia del derecho español que tenga efectos equivalentes y persiga una finalidad o intereses similares, si bien tal adaptación no tendrá más efectos que los dispuestos en el derecho del Estado de origen.

52. Las resoluciones judiciales extranjeras firmes no se reconocerán si concurren los motivos de denegación del reconocimiento del artículo 46 (1) LCJI, esto es: (a) cuando fueran contrarias al orden público; (b) cuando la resolución se hubiera dictado con manifiesta infracción de los derechos de defensa de cualquiera de las partes; (c) cuando la resolución extranjera se hubiere pronunciado sobre una materia respecto a la cual fueren exclusivamente competentes los órganos jurisdiccionales españoles o, respecto a las demás materias, si la competencia del juez de origen no obedeciere a una conexión razonable; (d) cuando la resolución fuera inconciliable con una resolución dictada en España; (e) cuando la resolución fuera inconciliable con una resolución dictada con anterioridad en otro Estado, cuando esta última resolución reuniera las condiciones necesarias para su reconocimiento en España; (f) cuando existiera un litigio pendiente en España entre las mismas partes y con el mismo objeto, iniciado con anterioridad al proceso en el extranjero.

53. Las resoluciones extranjeras que tengan fuerza ejecutiva en origen podrán ejecutarse en España una vez obtenido el exequátur [artículo 50 (1) CJI].

b) En materia concursal:

54. Si se considerase que el SoA forma parte o se presenta junto con un procedimiento vinculado a la insolvencia, se le aplicarían las normas sobre reconocimiento y declaración de ejecutividad de resoluciones judiciales previstas en los artículos 742 a 748 del Texto Refundido de la Ley Concursal (TRLC).

55. El artículo 744 TRLC prevé que cualquier resolución dictada en un procedimiento de insolvencia extranjero y que tenga su fundamento en la legislación concursal se reconocerá en España sin necesidad de procedimiento alguno, siempre que reúna los requisitos previstos en el artículo 742 TRLC. Por remisión, éste establece que las resoluciones extranjeras que declaren la apertura de un procedimiento de insolvencia se reconocerán en España mediante el procedimiento de exequátur regulado en la LCJI si reúnen los requisitos siguientes:

1. Que la resolución se refiera a un procedimiento colectivo fundado en la insolvencia del deudor, en virtud del cual sus bienes y actividades queden sujetos al control o a la supervisión de un tribunal o una autoridad extranjera a los efectos de su reorganización o liquidación.

2. Que la resolución sea definitiva según la ley del Estado de apertura.

3. Que la competencia del tribunal o de la autoridad que haya abierto el procedimiento de insolvencia esté basada en alguno de los criterios contenidos en esta ley o en una conexión razonable de naturaleza equivalente.

4. Que la resolución no haya sido pronunciada en rebeldía del deudor o, en otro caso, que haya sido precedida de entrega o notificación de cédula de emplazamiento o documento equivalente, en forma y con tiempo suficiente para oponerse.

5. Que la resolución no sea contraria al orden público español. 
56. Respecto a la posibilidad de que una sociedad española, con sede en España, solicitase la sanción de un SoA de refinanciación o reestructuración societaria ante un tribunal inglés, procede preguntarse si en ese caso sería posible oponerse a su reconocimiento, al entender controvertida la competencia del tribunal inglés por resultar contraria al Reglamento 848/2015, en el caso de que el COMI de la sociedad estuviera en España ${ }^{60}$.

\section{B) Reconocimiento de una transacción judicial}

57. Las transacciones judiciales extranjeras que hayan sido reconocidas se ejecutarán en España una vez obtenido el exequátur [artículo 51 LCJI]. Sin embargo, la LCJI silencia el mecanismo de reconocimiento de las transacciones judiciales. Podría interpretarse que deben seguir los mismos trámites previstos para las resoluciones judiciales (artículos 44-49 LCJI), por lo cual podrían invocarse los motivos de denegación del reconocimiento del artículo 46 (1) LCJI, o bien entender que se les aplica un régimen semejante al previsto para los documentos públicos con fuerza ejecutiva (artículos 56 y 57 LCJI), en cuyo caso contra ellos únicamente se podría objetar la falta de ejecutividad en el Estado de origen o su contrariedad con el orden público [artículos 46 (2) y 56 (1) LCJI].

\section{C) Reconocimiento de un acto de jurisdicción voluntaria}

58. Se le aplicarían las normas sobre reconocimiento y declaración de ejecutividad de resoluciones judiciales previstas en la LCJI, por remisión del artículo 12 (1) LJV. Conviene recordar, como ya expusimos, que el reconocimiento en España de los actos de jurisdicción voluntaria acordados por las autoridades extranjeras sólo se denegará en los casos previstos en el artículo 12 (2) LJV anteriormente indicados.

\section{Reconocimiento conflictual}

59. Algunos autores sostienen que los SoA sancionados por un tribunal inglés que se encuentren sometidos al Derecho inglés se reconocen en España utilizando el mecanismo del denominado reconocimiento conflictual o material, conforme al cual el SoA sería reconocido y produciría efectos en España en la medida en que haya sido adoptado por los tribunales del Estado cuya ley sea aplicable a los créditos afectados. Basada en el principio de unidad del régimen normativo, esta tesis encuentra su fundamento en el artículo 12 del Reglamento (CE) núm. 593/2008 del Parlamento Europeo y del Consejo, de 17 de junio de 2008, sobre la ley aplicable a las obligaciones contractuales (Roma I) ${ }^{61}$, según el cual la ley aplicable al contrato rige todo lo relativo al cumplimiento de esas obligaciones, las consecuencias de su incumplimiento, los diversos modos de extinción de las obligaciones y las consecuencias de la nulidad del contrato.

60. Conforme a los autores que defienden esta tesis, un SoA que sólo afectara a aquellos créditos sujetos a la Ley inglesa debería gozar del reconocimiento de su eficacia por una autoridad española, pues es difícil concluir que resultase contrario al orden público español ${ }^{62}$. Algunos autores incluso minimizan los riesgos intrínsecos del Brexit sobre el reconocimiento extraterritorial del SoA, en particular cuando se refieran a créditos sometidos al Derecho inglés ${ }^{63}$.

${ }^{60}$ E. Torralba Mendiola y Á. Carrasco, "Schemes of arrangement ingleses para sociedades españolas: una crítica", loc. Cit., pp. 359-362; L. Carballo Piñeiro, "La insolvencia transfronteriza en la Unión Europea y el Reino Unido tras el Brexit", loc. Cit., p. 509.

${ }^{61}$ DOUE L 177, de 4.7.2008.

${ }^{62}$ F. J. Garcimartín Alférez, “La eficacia en España de los schemes of arrangement ingleses”, loc. cit., p. 397.

${ }^{63} \mathrm{~J}$. WINDSOR, "El potencial impacto del Brexit en el mercado de las reestructuraciones y la insolvencia", Revista de derecho concursal y paraconcursal, 2019, núm. 31, pp. 387-396, esp. p. 394. 
61. No obstante, hemos de advertir las limitaciones de la tesis expuesta. En primer lugar, los mecanismos de reconocimiento y ejecución de la decisión inglesa de sancionar un SoA deben seguir las reglas establecidas para la eficacia extraterritorial de las decisiones judiciales extranjeras (sean resoluciones, transacciones o actos de jurisdicción voluntaria) que han sido enumeradas en el apartado anterior. El reconocimiento conflictual o material es una técnica de determinación del derecho aplicable que debe ser encuadrada en el ámbito del conflicto de leyes, pero no en el del reconocimiento de resoluciones judiciales extranjeras.

62. En segundo lugar, aún en la hipótesis de que debiera ser tenido en cuenta, el principio de unidad del régimen normativo y la aplicación de la lex contractus como regla general no opera de manera absoluta, sino que tiene excepciones. El propio Reglamento Roma I prevé el juego de conexiones autónomas o especiales para ciertos aspectos del derecho de crédito, como la posibilidad de someter determinados elementos de la relación entre el acreedor y el deudor a una Ley distinta (artículos 8-18 Reglamento Roma I). Algunos autores incluyen en estas excepciones los supuestos en que se produzca una novación subjetiva del deudor, como sucede en caso de una modificación societaria estructural surgida en el marco de una fusión ${ }^{64}$.

63. En tercer lugar, el artículo 1 (2) (f) Reglamento Roma I excluye de su ámbito de aplicación material las cuestiones pertenecientes al Derecho de sociedades relativas a la constitución o disolución de sociedades, así como la responsabilidad personal de los socios con respecto a las obligaciones de la sociedad. Un sector de la doctrina entiende que entre estas exclusiones podría encuadrarse un SoA que plantee una reestructuración societaria ${ }^{65}$, lo cual plantearía un problema para el reconocimiento conflictual de un SoA en los Estados miembros ${ }^{66}$.

64. En cuarto lugar, el deudor podría oponer el SoA a todos aquellos acreedores cuyo crédito esté sometido al Derecho inglés, pero no a aquellos acreedores cuyo crédito estuviese regido por otra ley extranjera, una interpretación que cuenta con precedentes judiciales ${ }^{67}$.

65. Por último, en situación de insolvencia del deudor, la regla lex fori concursus se impone a los efectos del procedimiento de insolvencia sobre los contratos vigentes en los que el deudor sea parte [artículo 7.2 (e) del Reglamento 848/2015]. En consecuencia, en una situación de insolvencia habría de tener en cuenta los efectos del proceso concursal sobre los contratos celebrados por el deudor, incluidos los acuerdos preconcursales de refinanciación o reestructuración societaria.

\section{Conclusiones}

66. A lo largo de este estudio se ha analizado la posibilidad de reconocer y ejecutar en España un SoA de Derecho inglés sancionado por un tribunal del Reino Unido en el doble escenario de que se haya iniciado antes o después del 31 de diciembre de 2020, fecha en que finaliza el período transitorio para la salida del RU de la Unión Europea. De esta fecha depende el instrumento utilizado para la obtención del reconocimiento, pues si el SoA se ha incoado antes del 1 de enero de 2021 podrán aplicarse los Reglamentos comunitarios; en caso contrario, se impone la aplicación del régimen autónomo español.

67. En todo caso, el reconocimiento del SoA está condicionado a la previa calificación del supuesto de hecho objeto de estudio aplicando las técnicas metodológicas propias del Derecho inter-

\footnotetext{
${ }^{64}$ F. J. Garcimartín Alférez, "La eficacia en España de los schemes of arrangement ingleses", loc. Cit., p. 392.

${ }^{65}$ J. Marshall, J. Ferguson y L. Aconley, "Brexit: what next for cross-border restructurings and insolvencies?”, loc. Cit., p. 151; R. SHELDON (ED.), Cross Border Insolvency, Bloomsbury, Londres, 2015, p. 507.

${ }^{66}$ L. CARballo PIÑEIRo, "Brexit and International Insolvency Beyond the Realm of Mutual Trust", International Insolvency Review, 2017, vol. 26, núm. 3, pp. 270-294, p. 293, disponible en <doi.org/10.1002/iir.1283>

${ }^{67}$ Sentencia del Oberlandgericht de Celle de 8.9.2009, Equitable Life, OLG Celle 8 U46/09. El juez alemán consideró que un SoA inglés relativo a créditos sometidos al Derecho alemán resultaba contrario al orden público alemán.
} 
nacional privado de los Estados miembros. Desde la óptica del sistema español, en este estudio hemos calificado la court's order sancionando un SoA desde una doble perspectiva: respecto de la naturaleza jurídica material de la institución como una cuestión de derecho civil y comercial, concursal o societaria; por otro lado, desde la perspectiva procesal, respecto de la consideración de la court's order como una resolución judicial, una transacción judicial o un acto de jurisdicción voluntaria.

68. La combinación de ambas calificaciones condiciona la técnica y la metodología jurídica a emplear para el reconocimiento y ejecución del SoA, dibujando una variedad de soluciones que auguran un escenario de cierta complejidad en el futuro inmediato en espera de que la jurisprudencia alumbre el camino en la era post-Brexit. 